\title{
Exploration of Tensile Properties of Low Carbon Steel Welded Joint
}

\author{
P. Senthilkumar \\ Lecturer, Department of Mechanical Engineering, Valivalam Desikar Polytechnic College, Nagapattinam, \\ Tamilnadu, India
}

\begin{abstract}
Article Info

Volume 8, Issue 4

Page Number: 49-55

Publication Issue :

July-August-2021

Article History

Accepted : 02 July 2021

Published: 09 July2021

The effect of welding current on the tensile properties of low carbon steel welded joint was investigated in this research. In this work mild steel plates were joined by shielded metal arc welding process which is also known as manual metal arc welding used to examine optimum welding current. The welded samples were cut and machined to standard configurations for tensile tests. It was concluded that variation of current affect the tensile properties of the low carbon steel welded joint. As the current increases from $80 \mathrm{~A}$ to $110 \mathrm{~A}$, the ultimate tensile strengths and yeild strength increases. The percentage elongation decreases with increase in welding current but increases at the welding current of 110A.

Keywords : SMAW, Low carbon steel, Welding current, E6013, Tensile properties.
\end{abstract}

\section{INTRODUCTION}

Shielded Metal Arc Welding is one of the most widely used welding processes. Also known as manual metal arc welding (MMAW), stick welding and flux shielded arc welding, it is simple arc welding process compare to other arc welding processes. The equipment is portable in size and can be shift from one place to the other. Consumable electrode used for this welding process. An electric current, in the form of either alternating current or direct current from a welding power supply, is used to form an electric arc between the electrode and the metals to be joined. The work piece and the electrode melts forming a pool of molten metal (weld pool) that cools to form a joint. The process is used primarily to weld iron and steels but aluminium, nickel and coppe $r$ alloys can also be welded with this method.

Steels are alloys of iron and carbon plus other alloying elements. Steel is commonly used in building construction, infrastructure such as bridge, tools equipment, machinery, ship, vehicle components and weapon. The carbon steels are divided into the following types depending upon the carbon content. 1.Low Carbon Steels contain up to $0.3 \%$ carbon 2.Medium Carbon Steels contain 0.3-0.6\% carbon. 3 . High Carbon Steels contain more than $0.6 \%$ carbon. Low carbon steel ( mild steel) is typically the most readily welded steel in a room temperature environment. Examples of low carbon steel suitable for welding include AISI1010, AISI1018, AISI1020, A36 etc. 


\section{Advantages of SMAW}

The process is widely used because of the following advantages:

* All kinds of light and heavy gauge metals can be welded.

* It can be used for fabrication, construction as well as maintenance works.

* All types of metals (ferrous, non-ferrous and alloys) can be welded.

* It permits a skilled operator to perform the welding operation quickly and easily.

* It is more suitable for short length welds.

* It is less expensive than the other processes.

* It is less sensitive to weld than the other arc welding processes.

* It is portable.

\section{Applications of SMAW}

* It is used for welding thin gauge as well as thick gauge metals in small and medium scale industries.

* Used in welding bridges, bus bodies, domestic items like grills for gate, windows, doors, chairs and tables.

* Used in welding roof structures for workshops, broken and cracked castings, water and oil tanks.

* Whenever welding is done in outdoor work, this process is very useful as a diesel generator welding set can be used.

* This process is used for reconditioning, hard facing, rectifying broken parts and repair welding.

\section{LITERATURE REVIEW}

N.D. Pandey et al [1] investigate the effect of submerged arc welding parameters and fluxes on element transfer behavior and weld-metal chemistry. It was concluded that the welding current and voltage have an appreciable influence on element transfer, as well as on weld composition. Weldments properties such as strength, toughness and solidification cracking behaviour are affected by chemical composition.

Edi Widodo et al [2] analyzed the effect of welding current on mechanical properties of the stainless steel joints using SMAW process. The current range of 70 A to $90 \mathrm{~A}$ was selected. The results depict that the tensile strength increased with the increase in welding current.

Oluwasegun Biodun Owolabi et al [3] performed the research on impact of welding current on mechanical properties of welded joints between mild steel and low carbon steel. The results showed that the welding current increases, hardness of the weld increases for the two samples up to $115 \mathrm{~A}$ and $116 \mathrm{~A}$ for mild steel and low carbon steel respectively but shows a decrease with a further increase in welding current. The ultimate tensile strength decreases with increase in welding current but increases at the welding current of $200 \mathrm{~A}$ and $115 \mathrm{~A}$ for mild steel and low carbon steel respectively. The yield strength and impact strength shows a decrease for the two samples with an increase in the welding current.

Rohit Jha et al [4] investigated the effect of welding current on the tensile properties of SMAW welded mild steel joints. The base material used is mild steel plate (AA10119 mild steel) of thickness $12 \mathrm{~mm}$ and E6013L is used as the electrode. From the results, it is observed that $120 \mathrm{amp}$ weldment depicted maximum ultimate tensile strength when compare to weldment of 100amp, 110amp, 130amp and 140amp. The tensile strength increases with increase in current up to 120 amp and start decreasing by further increment of current. The percentage elongation increases with increase in welding current up to $130 \mathrm{amp}$.

Apurv Choubey et al [5] conducted an experimental study to determine the influence of heat input on mechanical properties and microstructure of austenitic 202 grade stainless steel weldments 
produced by shielded metal arc welding (SMAW). From the experimental results it was found that the increase in heat input affects the micro-constituents of base metal, and heat affected zone (HAZ). Tensile strength decreases with increase in heat input and from scanning electron microscopy of tensile test fractured surfaces exhibited ductile \& brittle failure. From micro hardness data values it was observed that hardness of material increases with increase in heat input in weld pool and decreases in HAZ zone.

Rajeev Ranjan [6] investigated various process parameters of shielded metal arc welding. The process parameters considered are welding voltage, welding current and welding speed. Factorial design approach has been applied for finding the relationship between the various process parameters and weld deposit area. The study revealed that the weld deposit area varies directly with welding voltage and welding current and inverse relationship is found between welding speeds with weld deposit area.

J. O. Olawale et al [7] studied the correlate process variables in shielded metal-arc welding and post weld heat treatment on some mechanical properties of low carbon steel weld. Three hundred and sixty pieces of weld samples were prepared. The samples were welded together using E6013 electrodes. Varying welding current of 100A, 120A and 140A were used with a terminal voltage of $80 \mathrm{~V}$. The mechanical properties (tensile strength, impact strength and hardness) of specimens were tested. It is concluded that the current increases the hardness and strength increases but impact strength reduces.

Oladele Isiaka Oluwole et al [8] investigated the effect of welded joints on the mechanical properties of wrought (6063) aluminium alloy. The welding current (75A \& 100A) and arc voltage (25V \& 30V) were chosen as variable parameters. The weld samples were prepared for hardness, tensile and impact test. It has been observed that increase in welding current led to an increase in impact energy and ultimate tensile strength but impact strength decreases.

N. Kahraman et al [9] explained the effect of welding current on the plasma arc welding of pure titanium. Welding currents were chosen as $50 \mathrm{~A}, 55 \mathrm{~A}, 60 \mathrm{~A}$ and $65 \mathrm{~A}$. The experimental results show that increasing welding current increased the tensile strength of weld metal.

\section{MATERIALS AND METHODS}

\section{AISI 1018 Steel}

AISI 1018 steel is a mild low carbon steel with good ductility, toughness and strength qualities. This steel can be easily welded using most welding processes. Chemical composition of AISI 1018 steel given in table-1. The chemical composition of steel has impact on the weldability and the mechanical properties of the material.

Table-1: Chemical composition of AISI 1018 steel Chemical composition of AISI 1018 Steel

\begin{tabular}{|l|l|l|l|l|l|l|}
\hline \multicolumn{2}{|l|}{ Elements } & C & Mn & P & S & Fe \\
\hline Content & Min & 0.15 & 0.60 & - & - & Blance \\
\cline { 2 - 7 } & Max & 0.20 & 0.90 & 0.04 & 0.05 & Blance \\
\hline
\end{tabular}

\section{E6013 electrode}

E6013 is a low carton steel welding electrode with high titanium-potassium type coating, and suitable for both AC and DC. It is designed for medium to light penetration welding. E6013 is commonly used for automobile bodies, truck frames and bodies, metal furniture, bridges, storage tanks etc. Table 2 shows the chemical composition of E6013. The percentage of carbon increases, the tensile strength increases, the hardness increases, and ductility is reduced. E6013 have from 0.40 to 0.60 percent manganese. Increased manganese means increased hardness and tensile strength. Also, the percentage of silicon increases, tensile strength increases. 
Table-2: Chemical composition of E6013.

\begin{tabular}{|c|c|c|c|c|c|c|}
\hline \multicolumn{7}{|c|}{ Chemical composition (\%) } \\
\hline Elements & $\mathrm{C}$ & $\mathrm{Mn}$ & $\mathrm{Si}$ & $\mathrm{P}$ & $\mathrm{S}$ & $\mathrm{Fe}$ \\
\hline Content & 0.10 & $0.40-$ & 0.30 & 0.03 & 0.03 & Blance \\
& $\max$ & 0.60 & $\max$ & $\max$ & $\max$ & \\
\hline
\end{tabular}

E XXXX: The letter "E" indicates an electrode.

E 60XX: The first two digits indicate the minimum tensile strength. The "60" in E 6013 indicates that the weld metal will have a minimum tensile strength of 60000 psi.

E XX1X: The third digit indicates the different positions in which welding can be done using this electrode. In this case "1" in E 6013 means that the welding can be done in flat, overhead, horizontal and vertical (upwards).

E XXX3: The fourth digit indicates the type of flux coating used, penetration of the electrode and the type of current suitable for the electrode. In this case the " 3 " in E 6013 tells that it has a rutile potassium based flux coating. The penetration of the electrode is light and it can be used with AC and DC currents.

\section{Electrode Selection}

The electrode diameter selection is based on the work piece thickness, welding position, joint form, welding layer etc. Welding current level is determined by the size of electrode. Typical operating ranges for a selection of welding electrode sizes are illustrated in the table- 3 .

Table-3: E 6013 Welding rod amperage range

\begin{tabular}{|l|l|l|l|}
\hline \multicolumn{2}{|c|}{ Dia of rod } & \multicolumn{2}{c|}{ Amperage (A) } \\
\hline Inches & $\mathrm{mm}$ & Flat & $\begin{array}{l}\text { Vertical } \\
\& \\
\text { Overhead }\end{array}$ \\
\hline $3 / 32$ & 2.4 & $65-80$ & $65-75$ \\
\hline $1 / 8$ & 3.2 & $80-110$ & $80-95$ \\
\hline $5 / 32$ & 4.0 & $135-160$ & $120-140$ \\
\hline
\end{tabular}

\begin{tabular}{|l|l|l|l|}
\hline $3 / 16$ & 4.8 & $160-210$ & $140-160$ \\
\hline
\end{tabular}

\section{Experimental Method}

In this investigation the test specimen was prepared in two $150 \times 50 \times 06 \mathrm{~mm}$ thick steel plates pieces. These plates were cleaned from dirt, grease and other foreign materials to ensure good quality weld. The plates were welded together by the SMAW process employing basic coated electrodes.

\section{RESULTS AND DISCUSSION}

Welding current is the most influential variable in arc welding process, it is also the most important variable affecting melting rate, the deposition rate, depth of penetration and the amount of base metal melted. The tensile test results shown in table- 4 .

Table-4: Tensile test results

\begin{tabular}{|c|c|c|c|c|}
\hline S.No & $\begin{array}{c}\text { Current } \\
(\text { Amp })\end{array}$ & $\begin{array}{c}\text { Tensile } \\
\text { Strength } \\
(\mathrm{MPa})\end{array}$ & $\begin{array}{c}\text { Yield } \\
\text { Strength } \\
(\mathrm{MPa})\end{array}$ & $\begin{array}{c}\text { Percentage } \\
\text { of } \\
\text { Elongation }\end{array}$ \\
\hline 1 & 80 & 378.2 & 281.0 & 24.5 \\
\hline 1 & 90 & 389.7 & 287.8 & 23.7 \\
\hline 2 & 100 & 412.3 & 314.7 & 21.4 \\
\hline 3 & 110 & 424.1 & 335.9 & 21.9 \\
\hline
\end{tabular}

Effect of welding current on tensile strength

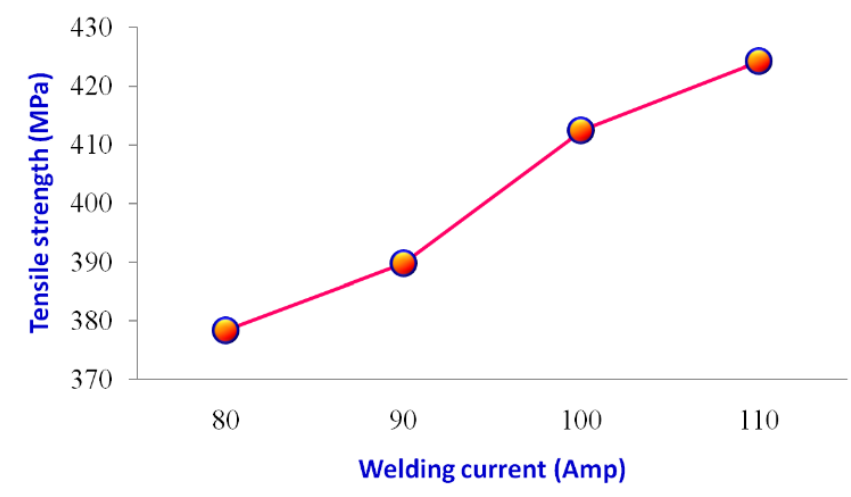

Figure-1: Effect of welding current on tensile strength 
Figure- 1 shows the effect of the welding current on the tensile strength of welded joint of low carbon steel samples. The tensile strength increases with increase in welding current up to $110 \mathrm{amp}$. At this maximum value of low carbon steel in figure-1, the rate at which the welding electrode is melted, the amount of base metal melted, dilution, depth of fusion, the amperage, the deposition rates, the depth of penetration was good at this value and optimum weldability was achieved. R.P. Singh et al [10] conducted the study on optimization of welding variables such as welding current, arc voltage and welding speed on a mild steel specimen. The relationship was determined between depth of penetration and welding variables. The results showed that depth of penetration increases by increasing the welding current. Rohit Jha et al [11] investigated the impact of current on the tensile properties of mild steel joints. The welding current was varied from 90A, 100A, 110A and 120 A. Results indicated that the tensile strength increases with increase in current up to $110 \mathrm{amp}$.

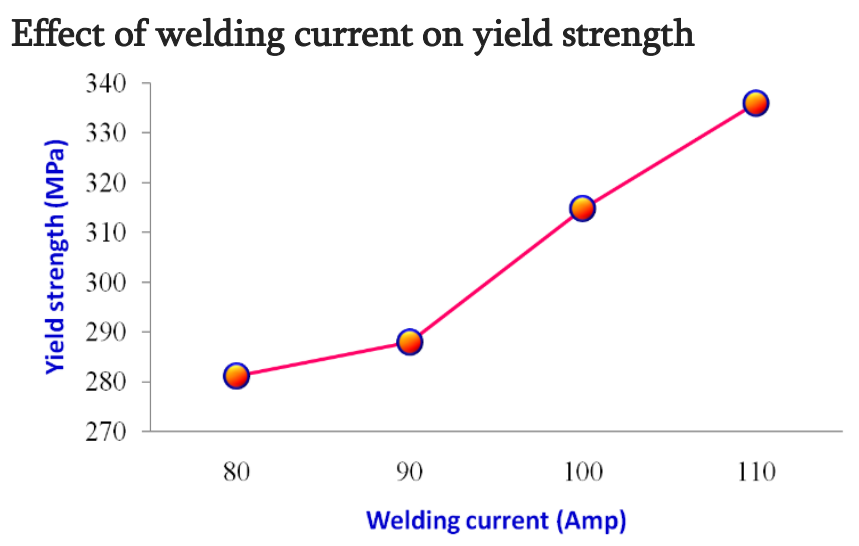

Figure-2: Effect of welding current on yield strength

Figure- 2 shows the yield strength of the welded steel at fixed voltage and varying current in the $\mathrm{V}$ groove edge welded sample. From this plot, the yield strength of the weldment increased with an increase in the current. The yield strength indicates that the welding current $80 \mathrm{~A}$ has the lowest tensile strength of 281.0
$\mathrm{MPa}$. at the current of $90 \mathrm{~A}$ obtained the yield strength value $287.8 \mathrm{MPa}$ which means having 6.8 $\mathrm{MPa}$ difference compared to the current of $80 \mathrm{~A}$. The highest yield strength $335.9 \mathrm{MPa}$ is obtained at welding current of $110 \mathrm{~A}$. The metal deposition rate is high at 110A, the weld geometry leads to enhancement of the yield strength of the welded structure compared to the current of $80 \mathrm{~A}, 90 \mathrm{~A}$ and 100A. Pravin Kumar Singh et al [12] conducted an experimental study to determine the influence of welding variables on mechanical properties of mild steel joints using SMAW process. The current range of $90 \mathrm{~A}$ to $110 \mathrm{~A}$ was selected. The experiment showed that the yield strength increases with increase in current up to $110 \mathrm{amp}$.

\section{Effect of welding current on percentage elongation}

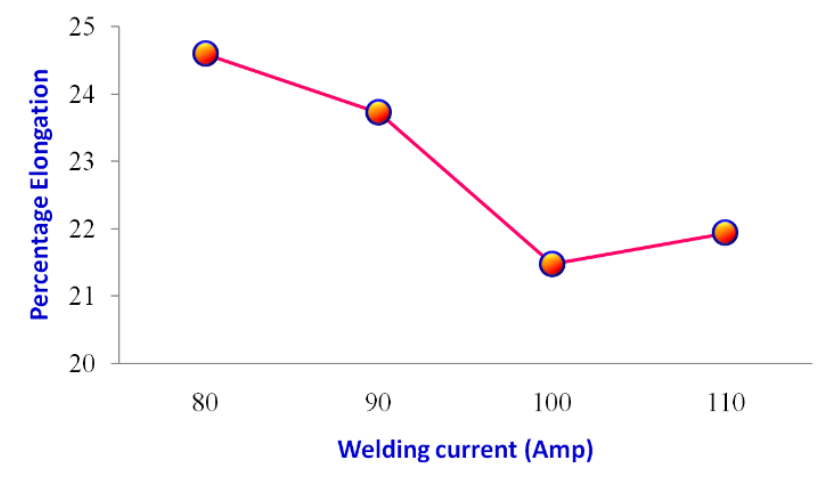

Figure-3: Effect of welding current on percentage elongation

Figure- 3 shows the effect of welding current on the percentage elongation of the welded joint made by SMAW. It is clear from figure that describes the percentage elongation of low carbon steel reduces with increase in welding current up to the current of $100 \mathrm{~A}$ and increases to 21.9 at $110 \mathrm{~A}$. The percentage elongation decreases when the ductility decreases and increases when ductility increases. A material's strength and its ductility are related. As strength increases, ductility decreases, and vice versa. Rohit Jha et al [11] investigated influence of welding current and joint design on the tensile properties of 
SMAW welded mild steel joints. The values of current were set at 90A, 100A, 110A and 120A. From the results, it was observed that $100 \mathrm{amp}$ weldment depicted minimum percentage elongation when compare to weldment of 90amp, 110amp and 120amp.

\section{CONCLUSIONS}

Low carbon steel plates were joined successfully by SMAW at various welding currents. The tensile test properties such as ultimate tensile, yield stress and percentage of elongation of welded joints are investigated. From this work, following are the conclusions.

$>$ The ultimate tensile strength and yield strength values of weld joints are increased with increase the welding current.

$>$ The percentage elongation has been minimum at welding current of $100 \mathrm{amp}$ in comparison with weld carried out of 80amp, 90amp and 110amp.

\section{REFERENCES}

[1]. N.D. Pandey, A. Bharti and S.R. Gupta, "Effect of submerged arc welding parameters and fluxes on element transfer behavior and weldmetal chemistry", Journal of Materials Processing Technology, Vol.42, 1994, pp.195211.

[2]. Edi Widodo, Iswant Iswanto, Mirtza Adi Nugraha, and Karyanik Karyanik, "Electric current effect on mechanical properties of SMAW-3G on the stainless steel AISI 304", MATEC Web of Conferences, 197, 12003 (2018)

[3]. Oluwasegun Biodun Owolabi, Sunday Christopher Aduloju, Chidiebere Sobechukwu Metu, Christian Ebele Chukwunyelu and Emeka Charles Okwuego, "Evaluation of the Effects of Welding Current on Mechanical Properties of Welded Joints Between Mild Steel and Low Carbon Steel", American Journal of Metallurgical and Materials Engineering, Vol. 1, No. 1, 2016, pp. 1-4.

[4]. RohitJha and A.K. Jha, "Investigating the effect of welding current on the tensile properties of SMAW welded mild steel joints", International journal of engineering research \& technology, Vol. 3, Issue. 4, 2014, pp.1304-1307.

[5]. Apurv Choubey and Vijaykumar S. Jatti, "Influence of Heat Input on Mechanical Properties and Microstructure of Austenitic 202 grade Stainless Steel Weldments', Wseas transactions on applied and theoretical mechanics, Vol. 9, 2014, pp.222-228.

[6]. Rajeev Ranjan, "Parametric Optimization of Shielded Metal Arc Welding Processes by Using Factorial Design Approach" International Journal of Scientific and Research Publications, Vol: 4, Issue: 9, 2014, pp:1-4

[7]. J. O. Olawale, S. A. Ibitoye, K. M. Oluwasegun, M. D. Shittu and R. C. Ofoezie, "Correlation between process variables in shielded metal-arc welding (SMAW) process and post weld heat treatment (PWHT) on some mechanical properties of low carbon steel welds", Journal of minerals and materials characterization and engineering, 11, 2012, pp.891-895.

[8]. Oladele Isiaka Oluwole and Omotoyinbo Joseph Ajibade, "Effect of Welding Current and Voltage on the Mechanical Properties of Wrought (6063) Aluminium Alloy", Materials Research, 13(2), 2010, pp.125-128.

[9]. N. Kahraman, M. Ta, skın, B. G"ulen, c, and A. Durgutlu, "An investigation into the effect of welding current on the plasma arc welding of pure titanium", Kovove Mater. 48, 2010, pp.179-184.

[10]. R.P. Singh, R.C. Gupta and S.C. Sarkar, "The Effect of Process Parameters on Penetration in Shielded Metal Arc Welding under Magnetic Field using Artificial Neural Networks", International Journal of Application or 
Innovation in Engineering \& Management, Vol:1, Issue:4, 2012, pp:12-17.

[11]. Rohit Jha and Dr. A.K. Jha, 'Influence of welding current and joint design on the tensile properties of SMAW welded mild steel joints," International Journal of Engineering Research and Applications, vol. 4, Issue 6, 2014, pp. 106111.

[12]. Pravin Kumar Singh, D. Patel and S.B. Prasad, "Optimization of process parameters during vibratory welding technique using Taguchi's analysis", Perspectives in Science 8, 2016, pp.399-402

\section{Cite this article as :}

P. Senthilkumar, "Exploration of Tensile Properties of Low Carbon Steel Welded Joint", International Journal of Scientific Research in Science, Engineering and Technology (IJSRSET), Online ISSN : 2394-4099, Print ISSN : 2395-1990, Volume 8 Issue 4, pp. 49-55, July-August 2021. Available at doi : https://doi.org/10.32628/IJSRSET218413 Journal URL : https://ijsrset.com/IJSRSET218413 